\title{
MADEIRAS TROPICAIS: ANÁLISE ECONÔMICA DAS PRINCIPAIS ESPÉCIES FLORESTAIS EXPORTADAS
}

\author{
Humberto ANGELO ${ }^{1}$, Alexandre Anders BRASIL ${ }^{2}$, Joaquim dos SANTOS ${ }^{3}$
}

RESUMO - Este trabalho trata do comportamento das exportações brasileiras de madeiras tropicais por espécie, no periodo de 1980-98. O desenvolvimento de modelos de tendência foi utilizado para estimar a taxa de crescimento e explicar o comportamento das exportações. As principais espécies tropicais exportadas nesse periodo foram, em ordem decrescente, mogno, jatobá, virola, cedro, angelim, ipê, andiroba, sucupira, tatajuba, cedrorana, assacu, cerejeira, paumarfím, freijó e jacarandá. Apenas seis espécies representaram $40 \%$ do volume e do valor total exportado. As espécies classificadas como outras aumentaram suas exportações na década de 90 . Espécies como mogno, virola, andiroba, sucupira e freijó apresentaram taxas decrescentes, ao passo que jatobá, cedro, ipê e cerejeira expandiram sua participação no mercado internacional de madeiras tropicais. O preço de todas as espécies mostra uma tendência positiva ao longo do período estudado e valores relativamente baixos, quando comparados ao preço do mogno.

Palavras-chave: Análise econômica, madeiras tropicais, exportações e Brasil.

\section{Tropical Wood: Economic Analysis of the Principal Exported Forest Species}

\begin{abstract}
This work analyses Brazilian tropical wood exports for principal forest species, over the period of 1980-98. Tendency models were built to estimate the growth rate and to explain the export performance for each species. The results pointed out that the principal tropical species exported were, in decreasing order, mahogany, jatoba, virola, cedar, angelim, ipe, andiroba, sucupira, tatajuba, cedrorana, assacu, cerejeira, pau-marfim, freijo and jacaranda. Only six species represented $40 \%$ of volume and total exported revenue. The species said less known increased their exports from 1991. The exported volume of mahogany, virola, andiroba, sucupira and freijo decreased, on the other hand jatoba, cedar, ipe and cerejeira have increased their share in the international market. About price, all studied species showed a positive tendency along studied period and value relatively low in comparison to the mahogany price..
\end{abstract}

Key-words: Economic analysis, tropical wood, exports, Brazil

\section{INTRODUÇÃO}

O Brasil possui quase um terço das florestas tropicais úmidas da Terra, o equivalente a 300 milhões de hectares. O país produz 9,86 milhões e consume 9,23 milhões de metros cúbicos de madeiras serradas tropicais, colocando-se, portanto, na liderança mundial de produção e consumo no setor (ITTO, 2000).

Vários pesquisadores têm estudado a estrutura, a produção e o mercado dos produtos da indústria de madeiras tropicais, dentre os quais devem se destacar os trabalhos de Mercado, (1980); Queiroz (1983); Santos (1988); Santos e Hummel (1988); Mercado e Campaganini (1988); Angelo e Silva (1997); Vicent

\footnotetext{
'Professor da Universidade de Brasília, Caixa Postal 04357, 70.910-900-Brasília - DF; e-mail: humb@zaz.com.br

${ }^{2}$ Mestrando em Ciências Florestais da Universidade Federal do Paranả; e-mail: brasil@floresta.ufpr.br

${ }^{3}$ Pesquisador do Instituto Nacional de Pesquisas da Amazônia, Caixa Postal 478, 69.011-970 Manaus-AM; e-mail: joca@inpa.gov.br
} 
(1992) e Angelo (1998).

Com relação às espécies tropicais, cerca de 700 espécies de madeira são conhecidas, mas é um pequeno número que representa $o$ grosso da comercialização (Santos e Hummel, 1988). Dentre as principais madeiras exportadas, encontram-se 0 mogno, o ipê, o cedro, o pau-marfim, a canafistula e a guaiuvira, cujo preço médio Fob, em 1998, variava de US\$ $610,00 / \mathrm{m}^{3}$ para o mogno a US\$ $302 /$ $\mathrm{m}^{3}$ para a canafístula (ITTO, 2000).

Dentre as espécies de maior valor comercial, Swetenia macrophylla, King (o mogno), é uma das mais valiosas da floresta tropical brasileira. No período de 1981 a 1993 , a participação do mogno representou de $35,32 \%$ do volume e $52,07 \%$ do valor da madeira serrada de folhosas tropicais brasileiras exportadas (Angelo, 1998). Por ser a espécie de maior valor comercial, vários autores têm estudado os seus aspectos mercadológicos (Browder, 1986; Veríssimo et al., 1995, Angelo e Silva, 1997; Terezo, 1999).

Desses trabalhos, pode-se concluir que o número de espécies comercializadas internacionalmente é pequeno e que, por outro lado, os preços e as quantidades ofertadas têm aumentado ao longo dos anos. No entanto, o mercado ainda desconhece os parâmetros da teoria econômica, como as funções de oferta e demanda de madeiras da região, a elasticidade dos produtos do complexo madeira no agregado e por espécie, os efeitos renda e substituição sobre a demanda das espécies e as externalidades resultantes da extração madeireira na floresta tropical. Essas informações sâo de grande valia aos produtores, à sociedade e principalmente ao governo, por ser este o responsável pelas políticas de produção, exportação e conservação da base florestal da região.

Este trabalho trata das exportações brasileiras de madeiras tropicais no periodo de 1980-98. Mais especificamente, analisa $o$ comportamento das exportações da madeira serrada tropical para diversas espécies florestais.

\section{MATERIAL E MÉTODOS}

A tendência é um elemento temporal das séries de preço que inclui influências bastante significativas ao longo dos anos. Os principais elementos que influenciam a oferta são o desenvolvimento e a difusão de novas tecnologias; já os principais elementos que influenciam a demanda são as tendências da população, a renda, o desenvolvimento de substitutos e a educação do consumidor (Brandt, 1980).

A função de tendência do preço, do valor e do volume das exportações pode ser explicitada como sendo:

$$
\begin{aligned}
& \ln P_{t}=\ln a+b T \\
& \ln V_{t}=\ln a+b T \\
& \ln Q_{t}=\ln a+b T
\end{aligned}
$$

em que

$\mathrm{P}_{\mathrm{t}}=$ preço $\mathrm{FOB}$ do produto no ano t, em US\$ / tonelada;

$\mathrm{Q}_{\mathrm{t}}=$ quantidade exportada do produto no ano $t$, em tonelada;

$\mathrm{V}_{1}=$ valor das exportações do 
produto no ano t, em US\$;

$\mathrm{T}=$ variável tendência, expressa em ano;

$\mathrm{a}$ e $\mathrm{b}=$ parâmetros a serem estimados.

De acordo com Brandt (1980), a taxa de crescimento (r) é dada a partir do modelo:

$$
\mathrm{r}=[(\text { antilog } \mathrm{b})-1] .100[4]
$$

Tomando o preço médio do mogno no período de $1980-98$ como referência, um índice de preço para as espécies foi construído. A expressão matemática para o cálculo desse índice é dada pela equação 5 :

$$
I P_{i}=\frac{P_{i}}{P M} \cdot 100
$$

em que

$\mathrm{IP}_{\mathrm{i}}=$ preço-índice da espécie $\mathrm{i}$ em relação ao preço médio da madeira de mogno;

$\mathrm{P}_{\mathrm{i}}=$ preço fob médio da espécie i no período de 1972-98, em US\$; e
$\mathrm{PM}=$ preço médio do mogno no período de 1972-98, em US\$.

A análise gráfica foi utilizada para verificar o comportamento das exportações de cada espécie. Esta análise mostra as variações ocorridas no mercado de madeira tropical, ao longo dos anos.

Os dados utilizados são anuais e compreendem o período de 1980-98, e as observações, coletadas na Secretaria de Comércio Exterior (SECEX), do Ministério da Indústria e Comércio, são referentes à madeira serrada de não-coníferas comercializada internacionalmente.

Foram estudadas 15 espécies e um conjunto de espécies denominado de "outras" pela SECEX, representaram $97,8 \%$ do volume das exportações no periodo de 1980-98. Essas espécies estão relacionadas na Tabela 1 , indicadas pelos nomes vulgar e científico e pela família.

Tabela 1. Exportações brasileiras de madeira tropical no periodo 1980-98, por espécie

\begin{tabular}{lll}
\hline NOME VULGAR & NOME CIENTífICO' & FAMÍLIA \\
\hline Andiroba & Carapa guianensis & Meliaceae \\
Angelim & Hymenolobium spp. & Fabaceae \\
Assacu & Hura crepitans & Euphorbiaceae \\
Cedro & Cedrela fissilis & Meliaceae \\
Cedrorana & Cedrelinga catanaeformis & Mimosaceae \\
Cerejeira & Amburana acreana & Fabaceae \\
Freijó & Cordia goeldiana & Boraginaceae \\
Ipê & Tabebuia spp. & Bignoniaceae \\
Jacarandá & Dalbergia spp. & Fabaceae \\
& Machaerium spp. & Fabaceae \\
Jatobá & Hymenaea spp. & Caesalpiniaceae \\
Mogno & Suietenia macrophyla & Meliaceae \\
Pau-martim & Balfourodendron riedelianum & Rutaceae \\
Sucupira & Bowdichia nitida & Fabaceae \\
Tatajuba & Bagassa guianensis & Moraceae \\
Virola (ucuúba) & Virola spp. & Myristicaceae \\
Outras & & \\
\hline
\end{tabular}

1 - Nomes científicos com base em Camargos et al. (1996). 
RESULTADOS E DISCUSSÃO

Noventa e sete países importaram a madeira brasileira no período de 1980-98. Em ordem decrescente os 15 primeiros estão apresentados na Tabela 2.

A Tabela 3 mostra a participação relativa de cada espécie no volume e no valor total exportado, bem como o preço médio no período. Quinze espécies representaram $46,33 \%$ do volume e $54,77 \%$ do valor total, o que equivale a um número pequeno de espécies utilizadas.

As espécies consideradas como "outras" somaram $51,48 \%$ do quantitativo e $41,72 \%$ do valor total. Em segundo lugar ficou o mogno, com $20,22 \%$ do volume e $33,61 \%$ do valor, seguido do jatobá, da virola, do cedro e do angelim. As espécies consideradas como outras, juntamente com o mogno, o jatobá, a virola, o cedro e o angelim, totalizaram $90 \%$ do volume e do valor exportado.

O preço médio pago pelas madeiras no periodo estudado foi de US\$ 383,70 por tonelada, inferior ao preço fob médio de US $\$ 466,00$ por tonelada pago a madeira serrada de coníferas do Brasil no mesmo período.

Tabela 2. Exportações brasileiras de madeira tropical no período 1980-98, por país importador

\begin{tabular}{lcc}
\hline \multicolumn{1}{c}{ PAÍS } & VOLUME (t) & VALOR (US $\$$ ) \\
\hline EUA & $293.463,44$ & $34.500 .054,00$ \\
França & $221.235,89$ & $35.969 .678,00$ \\
Reino Unido & $196.303,56$ & $23.708 .862,00$ \\
Espanha & $166.276,11$ & $16.812 .845,00$ \\
Portugal & $122.308,78$ & $6.918 .688,00$ \\
Holanda & $88.225,00$ & $9.086 .099,00$ \\
Argentina & $77.650,33$ & $4.896 .321,00$ \\
Itália & $73.503,22$ & $5.539 .851,00$ \\
Filipinas & $66.174,22$ & $9.630 .701,00$ \\
Tailândia & $63.116,67$ & $4.578 .450,00$ \\
Bélgica & $50.884,78$ & $6.711 .113,00$ \\
Japão & $24.351,89$ & $3.993 .297,00$ \\
Porto Rico & $20.720,89$ & $1.614 .460,00$ \\
Uruguai & $15.943,33$ & $2.359,298,00$ \\
Antilhas Holandesas & $15.405,56$ & $196.254,00$ \\
\hline
\end{tabular}

Fonte: SECEX/MICT e cálculo dos autores. 
Tabela 3. Volume, valor e preço da exportação de madeira serrada por espécie, no período de 1980-98

\begin{tabular}{|c|c|c|c|c|c|c|c|}
\hline \multirow{2}{*}{ ESPÉCIE } & \multicolumn{3}{|c|}{ VOLUME } & \multicolumn{3}{|c|}{ VALOR } & \multirow{2}{*}{$\begin{array}{l}\text { PREÇO } \\
\text { MÉDIO } \\
(U S \$ / t)\end{array}$} \\
\hline & $\begin{array}{l}\text { Absoluto } \\
\text { (t) }\end{array}$ & $\begin{array}{c}\text { Relativo } \\
(\%)\end{array}$ & $\begin{array}{c}\text { Acumu-lado } \\
(\%)\end{array}$ & $\begin{array}{c}\text { Absoluto } \\
\text { (US\$) }\end{array}$ & $\begin{array}{c}\text { Relativo } \\
(\%)\end{array}$ & $\begin{array}{c}\text { Acum u-lado } \\
(\%)\end{array}$ & \\
\hline Outras & $3.074 .488,10$ & 51,48 & 51,48 & $1.006 .608,30$ & 41,72 & 41,72 & 291.70 \\
\hline Mogno & $1.207 .841,30$ & 20,22 & 71,70 & $810.756,30$ & 33,61 & 75,33 & 667,20 \\
\hline Jatobá & $425.088,90$ & 7,12 & 78,82 & $120.283,50$ & 4,99 & 80,32 & 263,80 \\
\hline Virola & $316.281,40$ & 5,30 & 84,12 & $71.065,30$ & 2,95 & 83,37 & 261,10 \\
\hline Cedro & $214,047,70$ & 3,58 & 87,70 & $129,887,80$ & 5,38 & 88,75 & 487,70 \\
\hline Angelim & $117.038,60$ & 1,96 & 89,76 & $25.699,60$ & 1,07 & 89,72 & 217,40 \\
\hline Ipê & $111.609,00$ & 1,87 & 91,53 & $43.752,50$ & 1,81 & 91,53 & 312,70 \\
\hline Andiroba & $88.570,60$ & 1,48 & 93,01 & $21.923,10$ & 0,91 & 92,44 & 249,00 \\
\hline Sucupira & $83.999,40$ & 1,41 & 94,42 & $20,622,90$ & 0,85 & 93,39 & 255,80 \\
\hline Tatajuba & $82.980,00$ & 1,39 & 95,81 & $26.556,00$ & 1,10 & 94,49 & 286,10 \\
\hline Cedrorana & $44.248,40$ & 0,74 & 96,65 & $14.779,10$ & 0,61 & 95,00 & 285,70 \\
\hline Assacu & $28.986,50$ & 0,49 & 97,04 & $14.543,10$ & 0,60 & 95,60 & 249,90 \\
\hline Cerejeira & $23.265,60$ & 0,39 & 97,43 & $10.070,30$ & 0,42 & 96,02 & 415,70 \\
\hline Pau-marfim & $10.965,30$ & 0.18 & 97,61 & $3.927,30$ & 0.16 & 96,28 & 359,10 \\
\hline Freijó & $6.734,10$ & 0,11 & 97,72 & $2.763,00$ & 0,11 & 96,39 & 408,50 \\
\hline Jacarandá & $5.201,20$ & 0,09 & 97,81 & $4.925,70$ & 0,20 & 96,49 & $1.399,00$ \\
\hline TOTAL & $5.972 .146,20$ & 97,81 & & $2.412 .484,8$ & 96,49 & & \\
\hline
\end{tabular}

Fonte: SECEX/MICT e cálculo dos autores.

\section{Evolução do volume exportado}

A dinâmica do quantitativo das espécies tropicais mais exportadas pode ser observada na Figura 1. Um aumento expressivo das espécies classificadas como "outras" foi observado a partir de 1991. Este resultado evidencia que espécies diferentes das tradicionais estão sendo introduzidas no mercado internacional.

No período de 1994-98, as exportações do mogno e da virola cairam, respectivamente, 113 e $728 \%$; parte expressiva deste total pode ser atribuída à política de contingenciamento das exportações dessas espécies (Decreto 1.963/96; Decreto 2.687/98; e Portaria 71-N/94 do IBAMA e outras). A sucupira, a andiroba e o freijó também apresentaram constante queda no volume exportado.

Enquanto as exportações do mogno e da virola vêm declinando, espécies como o jatobá o, cedro, o ipê e a cerejeira aumentaram suas participações na pauta de exportação. De modo geral, a maioria das espécies apresentou tendência de crescimento, o que indica uma expansão da demanda internacional da madeira tropical brasileira no periodo estudado. 
JATOBÁ

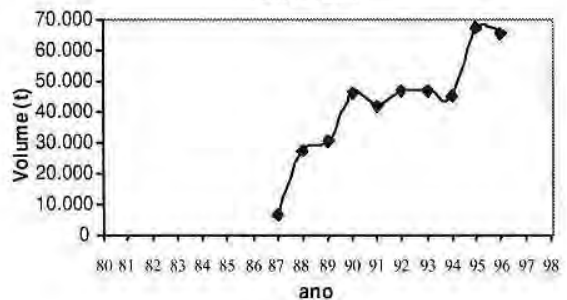

CEDRO

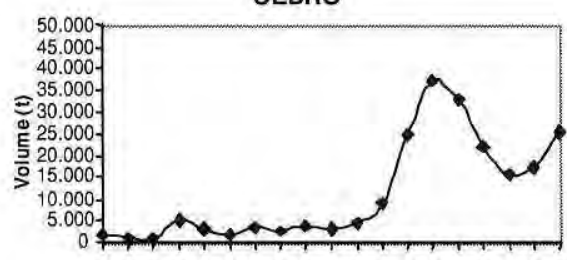

86) $81 \quad 82 \quad 83 \quad 84 \quad 8586 \quad 8788 \quad 89 \quad 9091 \quad 9293 \quad 9495 \quad 9697 \quad 98$ ano

IPE

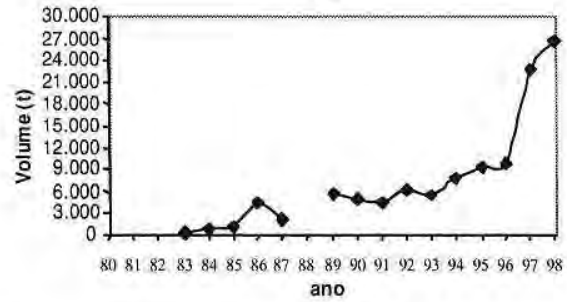

SUCUPIRA

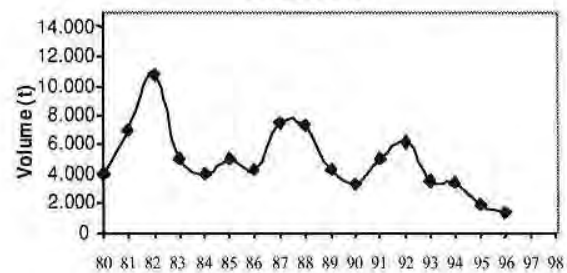
ano

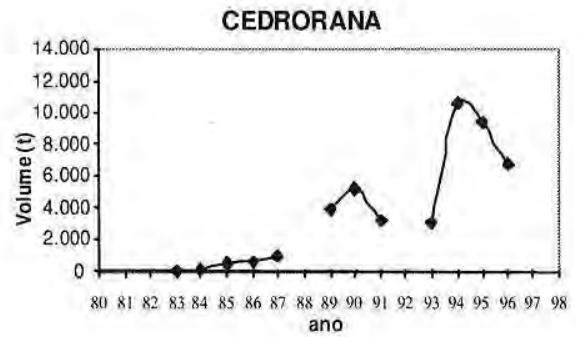

VIROLA

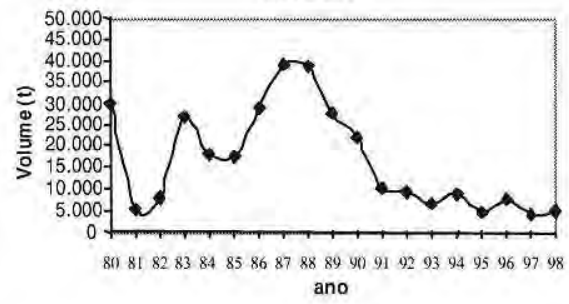

ANGELIM

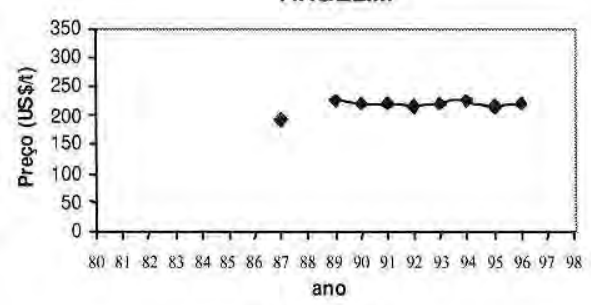

ANDIROBA

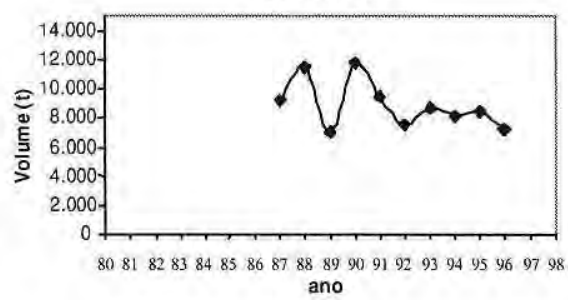

TATAJUBA

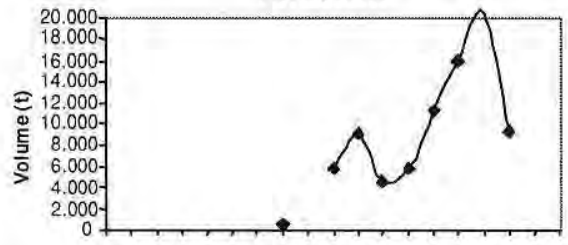

$8081 \quad 8283 \quad 8485868788899091 \quad 92939495969798$ ano

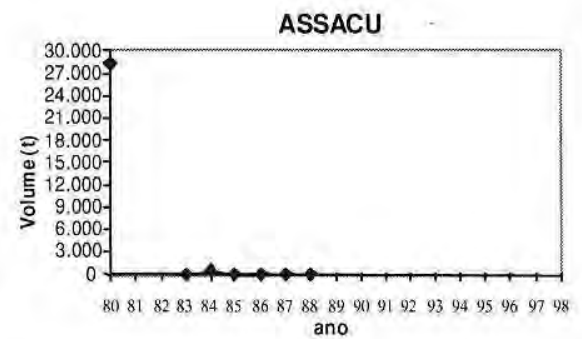

Figura 1. Evolução do volume exportado por espécie, em tonelada das madeiras tropicais brasileiras, no período de $1980-98$. 
Figura 1 - Continuação

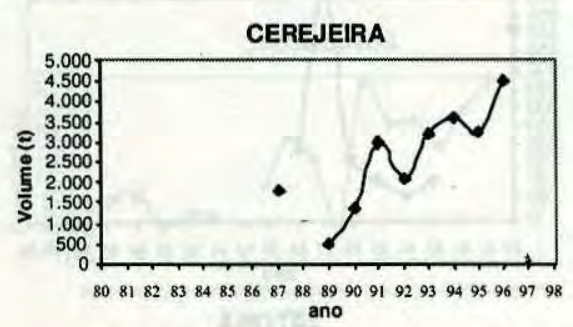

FREWÓ

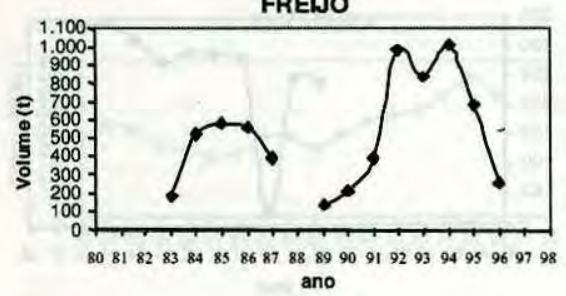

Evolução do preço

O comportamento do preço das principais espécies tropicais exportadas pode ser visto na Figura 2. Nota-se a tendência crescente nos preços de todas as espécies estudadas, no período 1980-98.

É importante observar que, após ligeiras quedas, os preços se recuperam, atingindo patamares maiores que os praticados anteriormente.

Exceto o jacarandá, as demais espécies apresentaram preço médio inferior ao do mogno (Tabela 4). Os baixos preços da madeira tropical têm sido um fator de desestímulo ao manejo florestal e um incentivo à oferta de madeira oriunda de florestas não-manejadas e de áreas de desmatamento.

As espécies que apresentaram preço-indice superior a $50 \%$ do preço do mogno foram: cedro (73), cerejeira
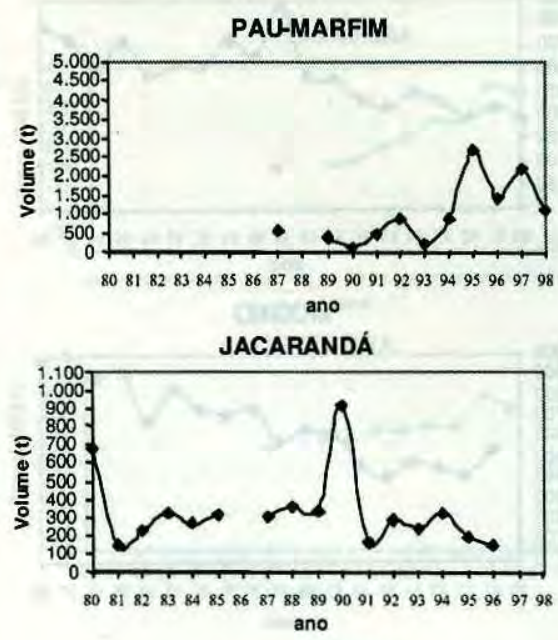

(62), freijó (61), pau-marfim (53). Espécies importantes como virola, ipê, jatobá, sucupira, tatajuba e angelim estavam subvalorizadas em relação ao preço do mogno.

\section{Análise de tendência}

As taxas geométricas de crescimento anual das principais espécies exportadas estão apresentadas na Tabela 5.

As espécies que registraram maior taxa de crescimento do volume e do valor foram cedrorana, tatajuba e ipê, enquanto jacarandá, andiroba e virola apresentaram taxas de crescimento negativa.

Exceto o assacu, as demais espécies apresentaram taxas de crescimento positivas para prȩ̧o, o que sinaliza a boa aceitação da madeira tropical no mercado internacional e a caracteriza como um bem superior.

Embora o mercado continue a 

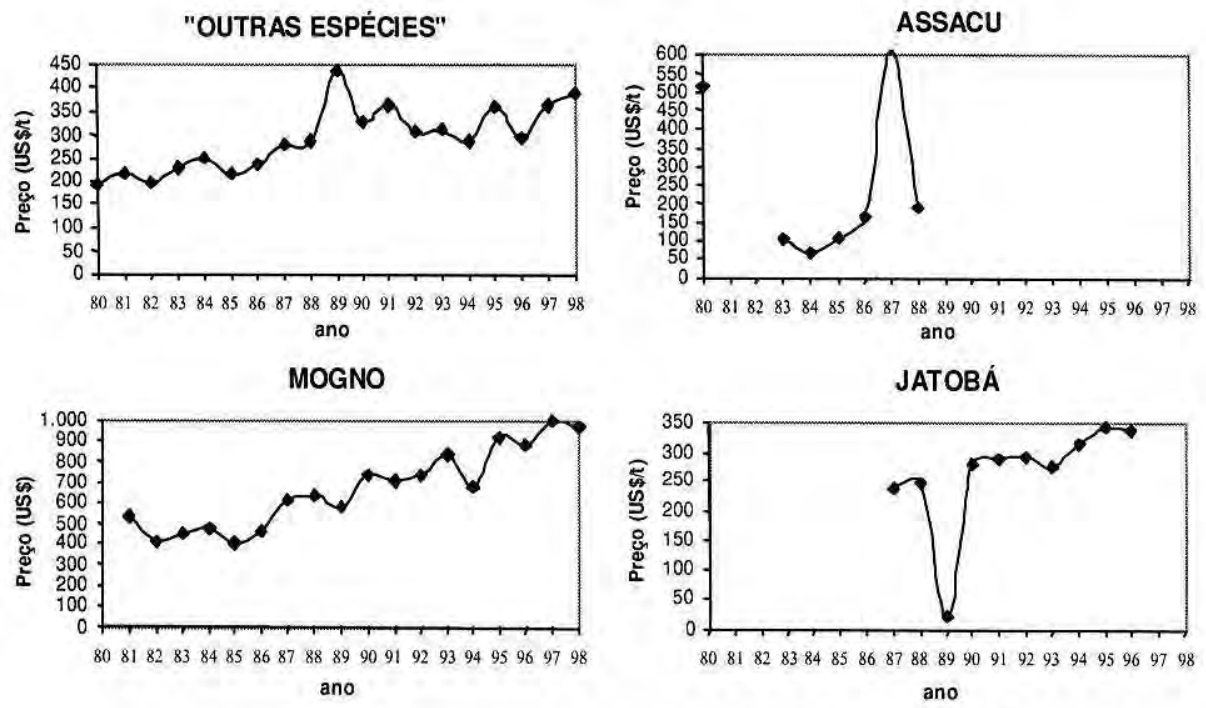

CEDRO

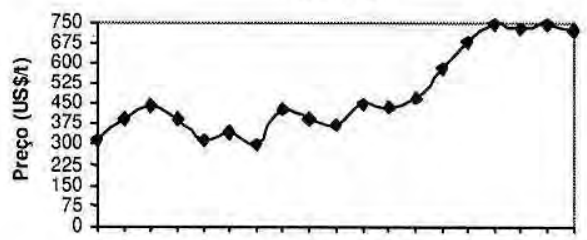

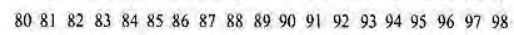
ano

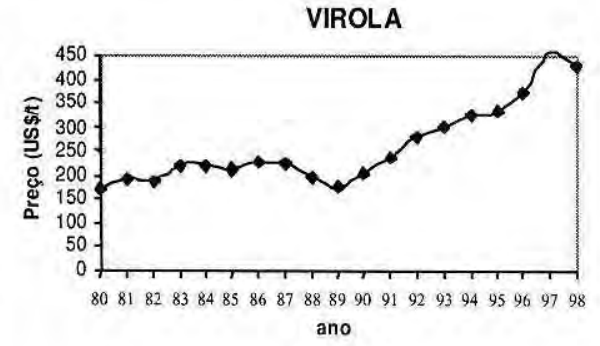

IPÊ
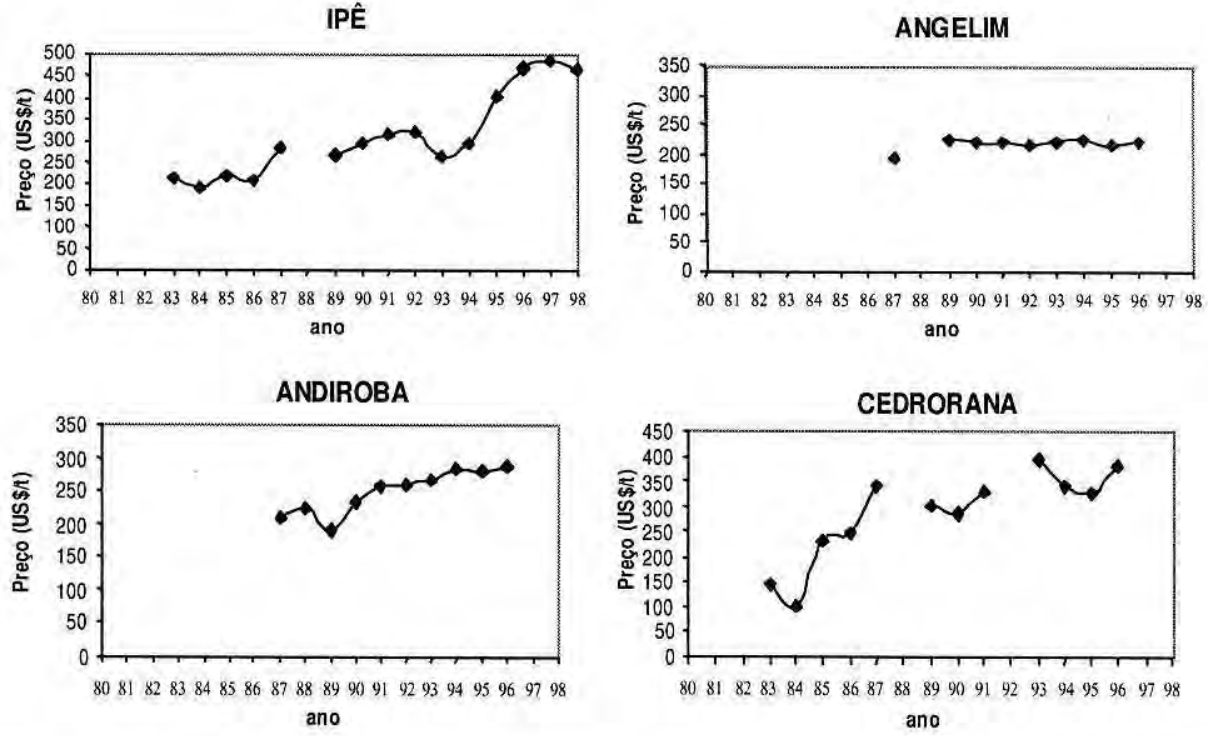

Figura 2. Evolução do preço FOB, por espécie, em dólar por tonelada das madeiras tropicais brasileiras, no período de 1980-98 
Figura 2 - Continuação

JACARANDÁ

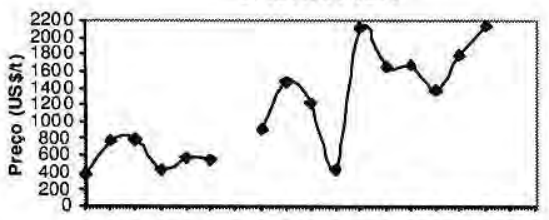

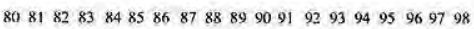
ano

SUCUPIRA

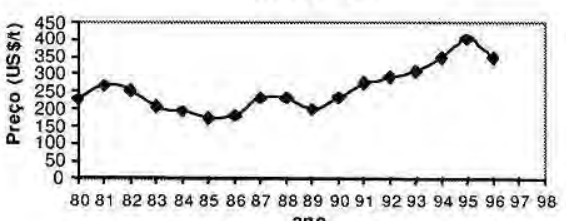

ano

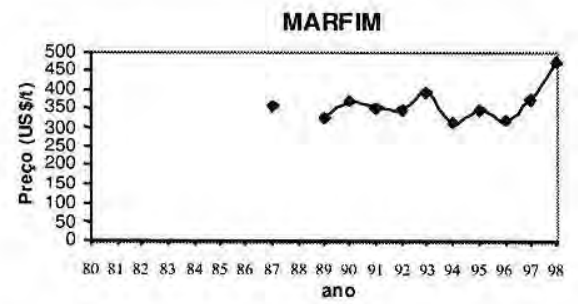

TATAJUBA

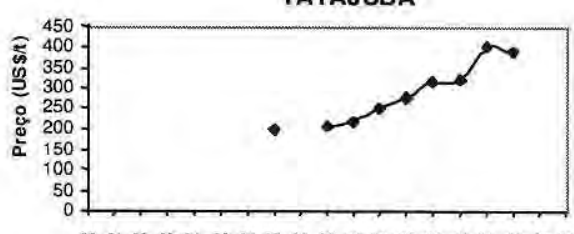

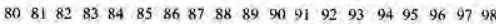
ano
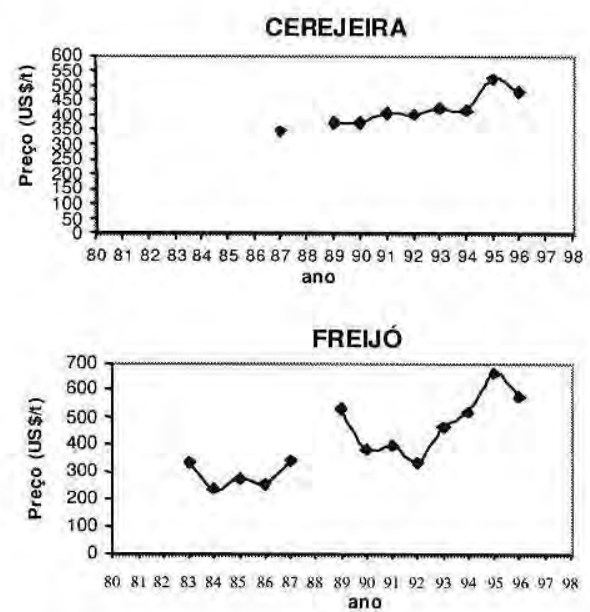

Tabela 4. Índice de preço das espécies tropicais brasileiras exportadas em relação ao preço do mogno, no período de 1980-98. Mogno $=100$

\begin{tabular}{|c|c|c|}
\hline ESPÉCIE & PREÇO MÉDIO (US\$) & INDICE \\
\hline Mogno & 667,02 & 100,00 \\
\hline Jatobá & 263,90 & 39,55 \\
\hline Virola & 261,01 & 39,14 \\
\hline Cedro & 487,70 & 73,10 \\
\hline Angelim & 217,50 & 32,59 \\
\hline Ipê & 312,70 & 46,87 \\
\hline Andiroba & 249,00 & 37,33 \\
\hline Sucupira & 255,90 & 38,35 \\
\hline Ta tajuba & 286,10 & 42,88 \\
\hline Cedrorana & 285,80 & 42,83 \\
\hline Assacu & 249,90 & 37,46 \\
\hline Cerejeira & 415,70 & 62,31 \\
\hline Pau-marfim & 359,10 & 53,83 \\
\hline Freijó & 408,60 & 61,24 \\
\hline Jacarandá & $1.140,00$ & 170,86 \\
\hline Outras & 291,70 & 43,72 \\
\hline
\end{tabular}

FONTE: SECEX/MICT e cálculo dos autores. 
praticar preços módicos para a madeira tropical, quando comparado com o preço médio da madeira serrada brasileira de coniferas para exportação (US\$ 466,00/t). As espécies que registraram maior taxa de crescimento anual em preço foram jatobá $(11,74 \%)$, jacarandá $(9,60 \%)$ e tatajuba $(9,10 \%)$.

A demanda de exportação crescente por madeira de jatobá, cedro, ipê e cerejeira, como pode ser verificado na Figura 1, pode ser explicada pelo preço relativamente baixo dessas espécies, quando comparado com o do mogno

Tabela 5. Estimativas das taxas de crescimento do volume, do valor e do preço das espécies de madeiras tropicais brasileiras exportadas, no período 1980-98

\begin{tabular}{lccc}
\hline ESPÉCIES & $\begin{array}{c}\text { TAXA CRESCIMENTO } \\
\text { VOLUME }(\%)\end{array}$ & $\begin{array}{c}\text { TAXA CRESC IMENTO } \\
\text { VALOR }(\%)\end{array}$ & $\begin{array}{c}\text { TAXA CRESC IMENTO } \\
\text { PREÇO }(\%)\end{array}$ \\
\hline Cedrorana & 46,29 & 57,24 & 7,48 \\
Tatajuba & 32,14 & 44,16 & 9,10 \\
Ipê & 26,70 & 34,11 & 5,85 \\
Angelim & 25,35 & 26,38 & 0,83 \\
Cedro & 20,87 & 26,76 & 4,87 \\
Assacu & 19,56 & 1,31 & $-1,28$ \\
Outras & 19,12 & 23,29 & 3,50 \\
Jatobá & 19,02 & 33,00 & 11,74 \\
Pau-martim & 18,93 & 20,24 & 1,11 \\
Cerejeira & 18,17 & 23,06 & 4,14 \\
Freijó & 4,49 & 11,11 & 6,34 \\
Mogno & 2,80 & 8,21 & 5,26 \\
Sucupira & 1,96 & $-2,90$ & 3,38 \\
Jacarandá & $-2,22$ & 7,16 & 9,60 \\
Andiroba & $-2,85$ & 1,31 & 4,29 \\
Virola & $-7,56$ & $-3,10$ & 4,83 \\
\hline TOTAL & 12,83 & 15,22 & 2,12 \\
\hline
\end{tabular}

(Tabela 5).

\section{CONCLUSÕES}

As madeiras tropicais mais exportadas pelo Brasil no periodo 1980-98 foram, em ordem decrescente, mogno, jatobá, virola, cedro, angelim, ipê, andiroba, sucupira, tatajuba, cedrorana, assacu, cerejeira, pau-marfim, freijó e jacarandá. Deve-se destacar o fato de as seis primeiras representarem $40 \%$ 
do volume e do valor total exportado.

As espécies classificadas como outras aumentaram sua participação no mercado internacional, a partir de 1991.

Enquanto as exportações do mogno, da virola, da andiroba, da sucupira e do freijó declinaram, as do jatobá, do cedro, do ipê e da cerejeira aumentaram sua participação na pauta das exportações brasileiras de madeiras tropicais.

O volume exportado das madeiras de cedrorana, tatajuba, ipê e angelim cresceu à taxa superior a $20 \%$ ao ano, no período $1980-98$. No entanto, o jacarandá, a andiroba e a virola apresentaram taxa negativa. Com relação ao valor, a maioria das espécies apresentou taxa de crescimento superior a $20 \%$ ao ano. No tocante ao preço, exceto o assacu, as demais espécies apresentaram taxa crescimento anual positiva, destacando-se o jatobá com $11 \%$, o jacarandá com $9,60 \%$ e a tatajuba com $9,10 \%$.

De modo geral, os resultados obtidos neste trabalho permitem concluir que o preço pago pela madeira tropical brasileira é relativamente baixo, quando comparado ao preço do mogno. Tal fato demonstra a necessidade de politicas florestal e industrial mais eficientes, a fim de aumentar o valor agregado da madeira tropical brasileira.

Por fim, recomenda-se a modernização do sistema de informações mercadológica sobre os produtos florestais brasileiros, não somente àqueles destinados à exportação, mas também aos que se destinam ao mercado doméstico.

\section{Bibliografia citada}

Angelo, H. 1998. As exportações brasileiras de madeiras tropicais. Tese de Doutorado, Universidade Federal do Paraná (UFPR), Curitiba, Paraná. 129p.

Angelo, H.; Silva; D.A. 1997. "As exportações brasileiras de mogno (Swetenia macrophylla, King)". Revista Arvore, 22(1):113-121.

ITTO. 2000. Annual Review and Assesment of the World Tropical Timber Situation. 1999. Yokohama: 118p. (Document GI-7/ 99).

Brandt, S.A. 1980. Comercialização agricola. Livroceres, Piracicaba, São Paulo. 195p.

Browder, J.O, 1986. Logging the Rainforest: A political economy of timber extraction and unequal exchange in the Brazilian Amazon. Thesis Ph.D., University of Pennsylvania, Pennsylvania, USA. 335p.

Camargos, J.A.A.; Czarneski, C.M.; Meguerditchian, I.; Iliveira, D. 1996. Catálogo de árvores do Brasil. IBAMA/ LPF, Brasília, Distrito Federal. 888p.

Mercado, R.S. 1980. A indústria madeireira na Amazônia: estrutura, produção e mercados. Tese de Doutorado, Michigan State University, Michigan, USA. Tradução: Maria Salete de Teixeira Guedes. n. p.

Mercado, R.S.; Campaganini, S. 1988. Exportações da floresta Amazônia. In: Encontro de Economia Florestal, 1. Anais... EMBRAPA/Centro Nacional de Pesquisa de Floresta, vol.1. Curitiba, Paraná. p.43-73.

Queiroz, E.S.P. 1983. Análise da indústria de beneficiamento primário de madeira no estado do Pará. Dissertação de Mestrado. Universidade Federal do Paraná, Curitiba, Paraná. 92p.

Santos, J. 1988. Diagnóstico das serrarias e das fábricas de laminados e compensados do 
estado do amazonas. Acta Amazonica, 18(1-2):67-82.

Santos, J.; Hummel, A.C. 1988. Situação das exportações de madeiras serradas, laminadas e compensadas do Estado do Amazonas (1984, 1985 e 1996). In: Encontro de Economia Florestal, 1, Anais... EMBRAPA/Centro Nacional de Pesquisa de Floresta, vol.2. Curitiba, Paraná. p.415-430.

SECEX. 1980/98. Ministério da Indústria do Comércio e do Turismo. Relatórios de Exportação. Brasilia, 1980/98.

Veríssimo, A.; Barreto, P.; Tarifa R.C. 1995. Uhl Extraction of a High-value Natural Resource in Amazônia: the Case of Mahogany. Forest Ecology and Management. 72: 39-60.

Terezo, E.F. de Moura. 1999. Status do mogno (Swetenia macrophilla, King) na Amazônia brasileira. www.mma.gov.br. Programa Nacional de Florestas - Agenda Positiva para o Setor Florestal. 35p.

Vicent, J.R. 1992. The tropical timber trade and sustainable development. Science, 256:1651-1656. 